\title{
Ethylene Insensitivity Impairs Resistance to Soilborne Pathogens in Tobacco and Arabidopsis thaliana
}

\author{
Bart P. J. Geraats, Peter A. H. M. Bakker, and L. C. van Loon \\ Graduate School Experimental Plant Sciences, Faculty of Biology, Section Phytopathology, Utrecht University, PO Box \\ 800.84, 3508 TB Utrecht, The Netherlands
}

Submitted 5 April 2002. Accepted 13 June 2002.

\begin{abstract}
Transgenic ethylene-insensitive tobacco (Tetr) plants spontaneously develop symptoms of wilting and stem necrosis when grown in nonautoclaved soil. Fusarium oxysporum, $F$. solani, Thielaviopsis basicola, Rhizopus stolonifer, and two Pythium spp. were isolated from these diseased Tetr plants and demonstrated to be causal agents of the disease symptoms. Pathogenicity of the two Pythium isolates and four additional Pythium spp. was tested on ethylene-insensitive tobacco and Arabidopsis seedlings. In both plant species, ethylene insensitivity enhanced susceptibility to the $P y$ thium spp., as evidenced by both a higher disease index and a higher percentage of diseased plants. Based on the use of a DNA probe specific for Pythium spp., Tetr plants exhibited more pathogen growth in stem and leaf tissue than similarly diseased control plants. These results demonstrate that ethylene signaling is required for resistance to different root pathogens and contributes to limiting growth and systemic spread of the pathogen.
\end{abstract}

Additional keywords: Chalara elegans, ein2, etr1, jar1, jasmonate, necrotrophic.

The gaseous plant hormone ethylene regulates developmental processes and is involved in interactions between the plant and its environment. For example, ethylene is involved in seed germination, growth of roots and shoots, xylem differentiation, formation of storage organs such as tubers and bulbs, flower development, fruit ripening, and senescence. Ethylene production is increased upon exposure to abiotic and biotic stresses, including extreme temperatures, drought, anaerobic conditions, wounding, herbivory, and infection by viral, bacterial, and fungal pathogens (Abeles et al. 1992).

The role of ethylene in plant-pathogen interactions seems ambiguous. Ethylene often has been reported to increase disease development. As ethylene promotes senescence, chlorosis, and necrosis, it could increase disease severity by causing or accelerating similar symptoms during pathogen attack. Exogenously applied ethylene increases disease severity of Verticillium wilt on tomato, and gray mold, caused by Botrytis cinerea, on rose, carnation, tomato, pepper, bean and cucumber (Boller 1991). In tobacco, increased ethylene levels stimulate the expansion of lesions caused by Tobacco mosaic virus (Knoester et al. 2001). Bent and associates (1992) reported reduced symptom development in the ethylene-insensitive Arabidopsis mutant ein2-1 after infection with virulent bacterial strains of Pseudomonas syringae and Xanthomonas campestris. Similarly, the ethylene-insensitive tomato mutant 'Never Ripe' shows reduced disease develop-

Corresponding author: B. P. J. Geraats, E-mail: B.P.J.Geraats@bio.uu.nl. ment after inoculation with Pseudomonas syringae, $X$. campestris, or the fungal pathogen Fusarium oxysporum (Lund et al. 1998).

Although ethylene can aggravate disease symptoms in various plant-pathogen interactions, its perception appears to be required for basal resistance to several bacterial and fungal pathogens. Hoffman and associates (1999) reported that ethylene-insensitive soybean mutants are more susceptible to Septoria glycines and Rhizoctonia solani. Similarly, Arabidopsis mutant ein2-1 shows enhanced susceptibility to $B$. cinerea (Thomma et al. 1999), Erwinia carotovora (Norman-Setterblad et al. 2000), Pseudomonas syringae, and $X$. campestris (Ton et al. 2002), in seeming conflict with the observations of Bent and associates (1992). As in ein2-1, enhanced susceptibility to $B$. cinerea is observed in the jasmonate-signaling mutant coil1 (Thomma et al. 1998). Conversely, treatment of wild-type Arabidopsis with either ethylene, its precursor ACC, or jasmonate (JA) increases resistance to $B$. cinerea (Thomma et al. 1999) and Pseudomonas syringae (Pieterse et al. 1998), associated with the activation of the plant defensin gene PDF1.2 (Penninckx et al. 1996, 1998; Pieterse et al. 1998). Moreover, the expression of the PDF1.2 gene after infection with $B$. cinerea depends on functional EIN2 and COI1 genes (Penninckx et al. 1996; Thomma et al. 1998, 1999). It has been generalized that, in Arabidopsis, basal resistance to different necrotrophic pathogens depends on both ethylene and JA signaling (Thomma et al. 2001a, b). Accordingly, the JA nonaccumulating triple mutant fad3-2 fad7-2 fad8 shows enhanced susceptibility to the necrotizing oomycete Pythium jasmonium (initially characterized as P. mastophorum; Vijayan et al. 1998). Similarly, the JA-insensitive jarl-1 mutant was found to be more susceptible to $P$. irregulare than wild-type plants (Staswick et al. 1998).

Knoester and associates (1998) reported that tobacco plants that are transformed with the mutant etrl-1 gene from Arabidopsis (transgenic ethylene-insensitive tobacco [Tetr] plants) manifest strongly reduced sensitivity to ethylene and develop wilting and stem necrosis when grown in potting soil. From these diseased Tetr plants, the fungi Rhizopus sp. and Thielaviopsis basicola (synanamorph Chalara elegans Nag Raj \& Kendrich) and the oomycetes $P$. splendens, $P$. sylvaticum, and two unidentified Pythium spp. were isolated. P. sylvaticum, prevalent in diseased Tetr plants, was tested for pathogenicity and demonstrated to be pathogenic on Tetr plants, but not on nontransformed control plants.

In this study, the extent to which Tetr plants are more susceptible to soilborne fungi than nontransformed tobacco plants was investigated. Several fungi and oomycetes were isolated from Tetr plants showing spontaneous symptoms of wilting and stem necrosis. These isolates were identified and tested for 
their pathogenicity on control and Tetr tobacco plants. To evaluate the role of ethylene perception in interactions with $P y$ thium spp. in more detail, different Pythium isolates were tested on control and Tetr tobacco. In addition, to elucidate if ethylene insensitivity enhances susceptibility to Pythium spp. in other plant species, the isolates were tested on wild-type and ethylene-insensitive mutants of Arabidopsis.

\section{RESULTS}

Tetr18 plants are infected by different root pathogens.

When grown in nonautoclaved soil, Tetr18 plants developed symptoms of wilting and stem necrosis between 5 and 12 weeks after germination. Nontransformed control plants growing in the same soil never developed symptoms of disease. Autoclaving the soil twice prior to sowing prevented disease development in Tetr18 plants. These observations are in full accordance with previously reported data (Knoester et al. 1998).

Stem pieces of Tetr18 plants showing moderate to severe symptoms of disease were surface sterilized, sliced transversely, and incubated on different agar media. Fungal or oomycetous outgrowth was transferred to fresh media. In all, 46 isolates were obtained, including 15 morphologically different fungi or oomycetes. Six isolates were identified as Thielaviopsis spp., 10 as Fusarium spp., 12 as Pythium-like, 2 as $\mathrm{Mu}$ cor/Rhizopus-like, and 16 as Penicillium spp., Aspergillus spp., or unknown. One representative of each morphologically different group was selected and tested for pathogenicity on 6week-old control and Tetr18 tobacco plants. Six of these isolates caused symptoms of wilting or stem necrosis in Tetr18 plants, and all six could be reisolated from stem tissue of diseased plants (Table 1). None of these isolates caused disease symptoms on control tobacco plants.

Tetr18 plants show increased susceptibility to Pythium spp.

Because plants are generally more susceptible to Pythium infection at the seedling stage (Martin and Loper 1999), 2-weekold control and Tetr18 seedlings were tested for their susceptibility to different Pythium spp. Roots were dipped in a mycelial suspension of the Pythium isolates Nt15d and Nt59d (Table 1), as well as four additional selected Pythium spp.: P. sylvaticum, isolated previously from diseased Tetr tobacco (Knoester et al. 1998); P. irregulare and P. jasmonium, both isolated from Arabidopsis (Staswick et al. 1998; Vijayan et al. 1998); and P. aphanidermatum, isolated from cucumber (Postma et al. 2000) and described as pathogenic on tobacco (Chen et al. 1996). Disease development was monitored for 18 days. Control seedlings of nontransformed and Tetr18 tobacco that were mock inoculated with distilled water never developed symptoms of disease. When inoculation was performed with the aggressive Pythium isolate Nt59d, both control and Tetr18 plants developed symptoms of wilting and necrosis within a few days. Thereafter, a substantial percentage of the plants died. The mortality rate of Tetr18 plants was two- to threefold higher than that of control plants, clearly reflecting their enhanced susceptibility to isolate Nt59d (Fig. 1A). Some other Pythium isolates were less virulent and did not cause plant death; thus, a different parameter to describe disease severity was required. Therefore, a disease index was used that took into account the extent of wilting and stem necrosis (Fig. 1B). However, individual plants differed in their behavior in that, after initial development of disease symptoms, some plants recovered, whereas others did not. This phenomenon is masked when disease development is expressed by the index, but becomes manifest when the percentage of diseased plants is used as a parameter (Fig. 1C). The latter method of
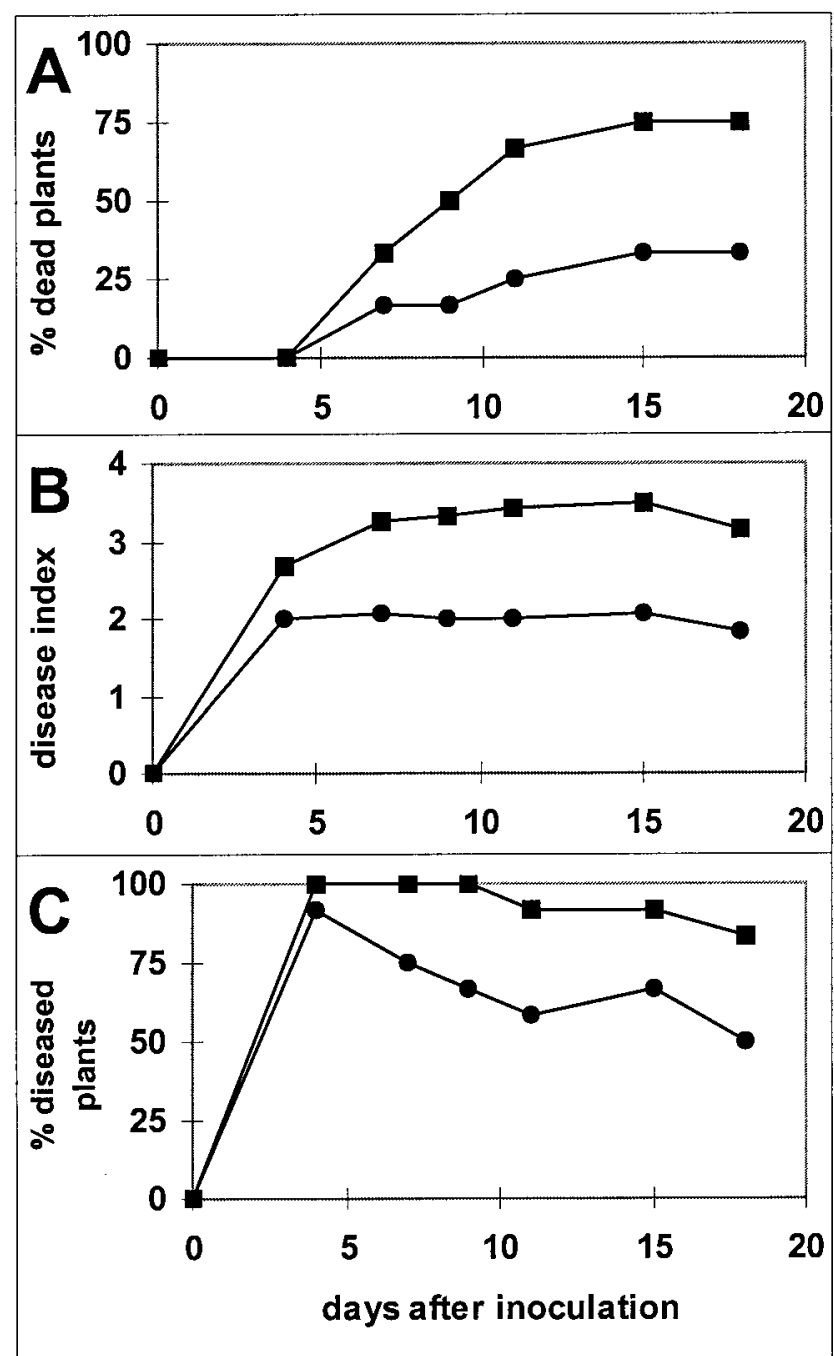

Fig. 1. Disease development of control $(\bullet)$ and transgenic ethyleneinsensitive tobacco (Tetr18) (ם) plants after inoculation with Pythium isolate Nt59d presented as $\mathbf{A}$, percentage of dead plants and $\mathbf{B}$, disease index scale 0 to 4 . $0=$ no symptoms of wilt; $1=$ less than $30 \%$ of leaves wilting; $2=$ more than $30 \%$ of leaves wilting, sometimes first symptoms of stem necrosis; 3 = all leaves wilting and moderate to severe necrosis of stem (and leaf) tissue; 4 = plant completely necrotic. C, Percentage of diseased plants (plants within scale 1 or higher of the disease index shown in B).

Table 1. Isolates causing symptoms of wilting or stem necrosis on Tetr18 tobacco plants growing in nonautoclaved soil ${ }^{\mathrm{a}}$

\begin{tabular}{llc}
\hline Isolate & \multicolumn{1}{c}{ Species } & Taxonomic class \\
\hline Nt15d & Pythium sp. "group HS" & Oomycetes \\
Nt59d & Pythium sp. "group G" & Oomycetes \\
Nt60c & Rhizopus stolonifer (Ehrenberg: Fries) Vuillemin & Zygomycetes \\
Nt32d & Fusarium oxysporum Schlechtendahl: Fries & Ascomycetes \\
Nt34b & Fusarium solani (Martius) Saccardo & Ascomycetes \\
Nt29 & Thielaviopsis basicola (Berkeley \& Broome) Ferraris & Ascomycetes \\
\hline
\end{tabular}

${ }^{\mathrm{a}}$ Tetr $=$ transgenic ethylene-insensitive tobacco plants. Isolates were identified by the Fungal Biodiversity Center (CBS), Utrecht, The Netherlands . 
presentation clearly distinguishes control from Tetr18 plants and is most informative about the dynamics of disease development. Therefore, this parameter was used to quantify disease development in all further bioassays.

As with Pythium isolate $\mathrm{Nt59d}$, inoculation with isolate Nt15d resulted in a significantly higher percentage of diseased Tetr18 than control plants, when tested with repeated-time measures (Fig. 2). Inoculation with $P$. irregulare, $P$. jasmonium, and $P$. sylvaticum caused symptoms in Tetr18 plants but not in control plants. However, the latter two isolates caused symptoms in a small percentage of plants only. Only the increase in disease development upon inoculation with $P$. irregulare was significant, using repeated-time-measures statistics. The pathogen $P$. aphanidermatum caused almost $100 \%$ of both control and Tetr 18 plants to become diseased. However, when disease pressure was reduced, the percentage of diseased plants was decreased more strongly in control than in Tetr18 plants (Fig. 3). Thus, Tetr18 is also more susceptible than control tobacco to $P$. aphanidermatum.

After 18 days, plants with disease symptoms as well as most plants that had recovered from initial wilting symptoms were reduced in size. Pythium infections that resulted in a significant percentage of diseased plants (Fig. 2) also caused a significant reduction in plant shoot weights (Fig. 4), irrespective of the Pythium isolate used.

\section{Pythium isolate Nt59d colonizes shoot tissue of Tetr18 more effectively.}

To investigate whether the enhanced symptom development of Tetr18 plants correlates with an increased growth of $P y$ - thium spp. in the shoot tissue, a specific probe was developed to detect the 5.8S rRNA of the pathogen. In the first experiment, 200 2-week-old seedlings of control and Tetr18 tobacco were inoculated with Pythium isolate Nt59d. After 5 days, the amount of pathogen-specific RNA was estimated in plants with different disease severities (disease indexes 0 to 4; Fig. 5A). The distribution of plants in classes with disease indexes $0,1,2,3$, and 4 was $45,17,16,19$, and $3 \%$, respectively, for control plants, and 12, 7, 7, 37, and $37 \%$ for Tetr18 tobacco. When plants with the same disease index (d.i.) were compared, Tetr18 plants contained substantially more pathogenspecific RNA in the shoot tissues than control plants. The pathogen was detected in Tetr18 plants with moderate symptoms of disease (d.i. $=2)$; whereas, in control plants, the pathogen was detected only in severely diseased plants $($ d.i. $=3)$. RNA of seedling roots could not be isolated because of the small root mass and degradation of the RNA in rotting tissue. The completely necrotic control seedlings $($ d.i. $=4)$ were too few for analysis.

In order to obtain more tissue for RNA extraction, 85 4week-old control and Tetr 18 plants were inoculated in a similar experiment (Fig. 5B). Of the control plants, only $8 \%$ had developed slight symptoms of disease $($ d.i. $=1)$ after 5 days. In contrast, almost all Tetr18 plants were diseased at this time point, with a distribution in classes with disease indexes 0,1 , 2,3 , and 4 of $5,1,5,5$, and $84 \%$, respectively. Pathogen-specific RNA was not detected in control plants, including those with d.i. $=1$. In contrast, the pathogen was detected in Tetr18 plants with d.i. $=1$. This also was true for Tetr18 plants with

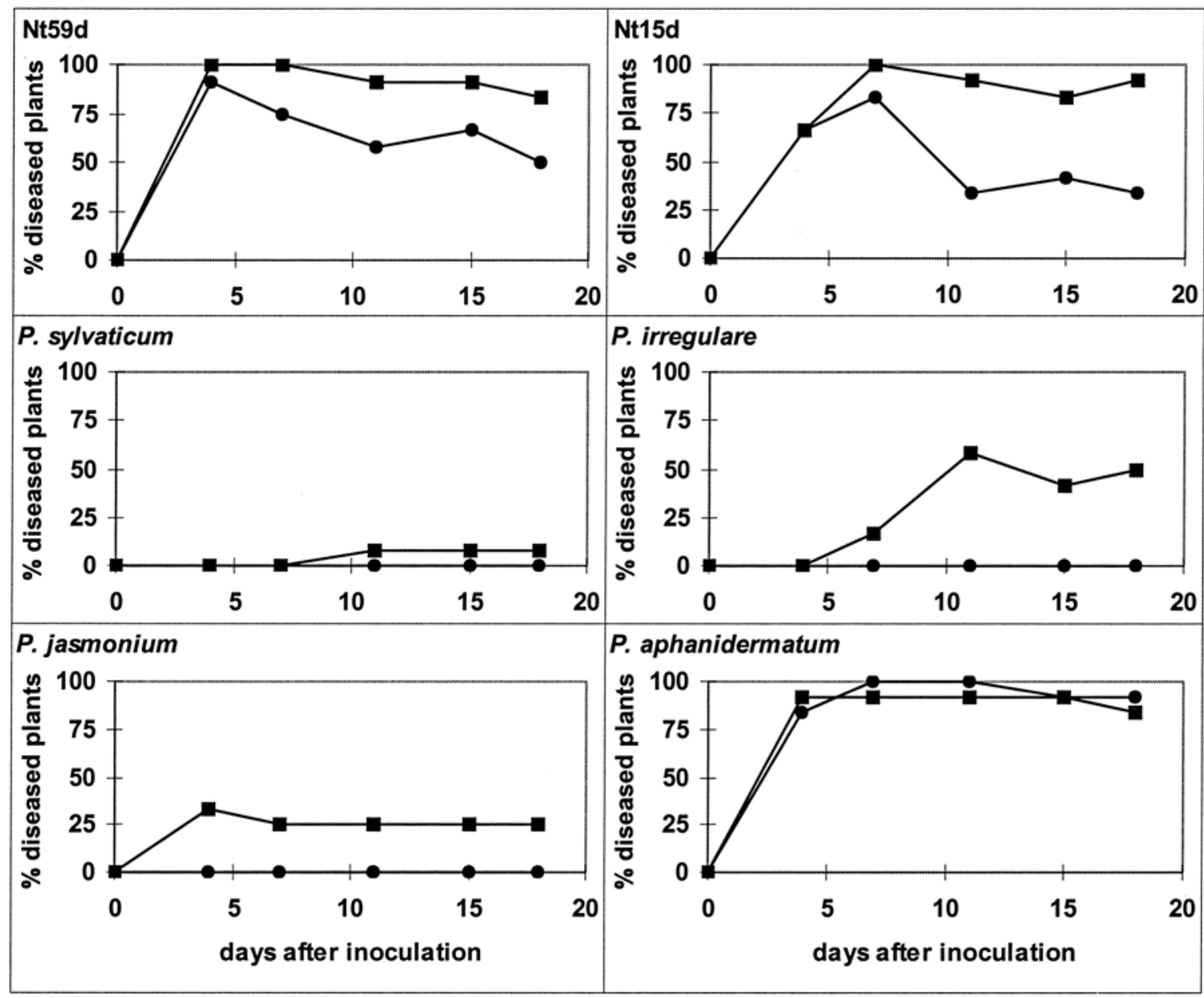

Fig. 2. Percentage of control (O) and transgenic ethylene-insensitive tobacco (Tetr18) (ם) plants showing disease symptoms after inoculation with different Pythium isolates. 
d.i. $=2$ to 4 . Tetr 18 plants with d.i. 3 and 4 contained relatively high levels of pathogen-specific RNA and low levels of tobacco-specific RNA, probably as a result of increased amounts of the pathogen and degradation of tobacco RNA due to tissue necrosis. These data demonstrate that growth of the pathogen in the shoot tissue of Tetr18 plants is increased compared with control plants.

To investigate if Pythium isolate Nt59d infects not only the root but also the shoot tissue of Tetr18 plants more readily than that of control plants, tobacco stems were wound inoculated by needle-pricking through a droplet of Pythium suspension. Control plants never developed symptoms. In contrast, some Tetr18 plants developed severe symptoms of stem rot and wilting within 3 days, but the percentage of diseased plants never exceeded $50 \%$ (data not shown). All Tetr18 plants that developed symptoms died within a week. These results demonstrate that Tetr18 plants also are more susceptible to stem infection by Pythium spp. than control plants.

\section{Arabidopsis ein2-1 mutants show increased susceptibility to Pythium spp.}

To study if ethylene insensitivity also results in increased susceptibility to Pythium spp. in other plant species, the six Pythium isolates were tested on wild-type Arabidopsis plants and three of its mutants. The etr $1-1$ mutant was used because it provided the mutant gene for the Tetr tobacco transformants. The ethylene-insensitive mutant ein2-1 was used in addition, because triple-response assays revealed that this mutant had a stronger ethylene-insensitive phenotype than etr1-1. Growing etrl-1 seedlings on agar medium containing $5 \mu \mathrm{M} 1$-aminocyclopropane-1-carboxylic acid (ACC) resulted in a significant reduction in hypocotyl length compared with seedlings growing on medium without ACC (Fig. 6). In contrast, ein2-1 mutants did not show hypocotyl shortening at this ACC concentration. The isolates of $P$. irregulare and $P$. jasmonium that are used in this study were isolated from diseased JA-insensitive (jar1-1; Staswick et al. 1998) and JA-nonaccumulating (fad3-2 fad7-2 fad8; Vijayan et al. 1998) Arabidopsis mutants, respectively. Therefore, jarl-1 was used as a positive control to check the pathogenicity of these isolates.

Comparable to tobacco, Arabidopsis seedlings inoculated with Pythium spp. developed symptoms of wilting, necrosis, and growth reduction. Inoculation of etrl-1 plants never resulted in more plants with disease symptoms than inoculated wild-type plants. However, as tested with repeated-time measures, isolates Nt15d, Nt59d, $P$. sylvaticum, $P$. jasmonium, and $P$. irregulare did cause significantly more disease symptoms in mutants ein2-1 and jarl-1 than in wild-type plants (Fig. 7). Wild-type plants showed hardly any disease symptoms upon inoculation with isolate Nt15d, $P$. sylvaticum, or $P$. aphanidermatum, and largely recovered within 2 weeks after inoculation with isolate $\mathrm{Nt} 59 \mathrm{~d}, P$. irregulare, or $P$. jasmonium. As observed in tobacco, a negative correlation between the percentage of diseased plants and the final average fresh weight was present in Arabidopsis plants. By 19 days after inoculation, most wild-type plants did not show symptoms of disease anymore. However, the shoot weights were significantly reduced upon treatment with all isolates except $P$. sylvaticum (Fig. 8), indicating that the pathogens had affected the plants at earlier time points.

\section{DISCUSSION}

Several fungi and oomycetes were isolated from diseased Tetr18 plants growing in nonautoclaved potting soil, including Pythium spp., Rhizopus sp., T. basicola, and Fusarium spp. These results confirm the earlier observations by Knoester and associates (1998), who isolated Pythium spp., Rhizopus spp., and T. basicola from spontaneously diseased Tetr plants. The isolates caused symptoms of disease in ethylene-insensitive tobacco plants when applied as agar plugs with mycelium at the stem base of 5-week-old plants. Such inoculation of nontransformed control plants never resulted in development of disease symptoms. This demonstrates that basal resistance to these root pathogens is strongly impaired in ethylene-insensitive tobacco plants.

When different Pythium spp. were applied in a different manner (i.e., as dense mycelial suspensions) to 2-week-old seedling roots, isolates $\mathrm{Nt} 15 \mathrm{~d}$ and $\mathrm{Nt} 59 \mathrm{~d}$ caused symptoms of disease in control plants too, although to a lesser extent than in Tetr18 plants. This indicates that these isolates can act as pathogens of tobacco under seedling conditions or at high inoculum density. The low number of Tetr18 seedlings developing symptoms of wilt after inoculation of the roots with $P$. irregulare, $P$. jasmonium, or $P$. sylvaticum (Fig. 2 ) and the lack of symptom development in control seedlings suggests a relatively low pathogenicity of these isolates on tobacco. The isolate of $P$. sylvaticum used was described previously to be very virulent on Tetr18 tobacco (Knoester et al. 1998). Apparently, this isolate had lost most of its virulence during storage.

Tobacco seedlings developed symptoms of wilting and necrosis within a few days upon inoculation with Pythium isolate

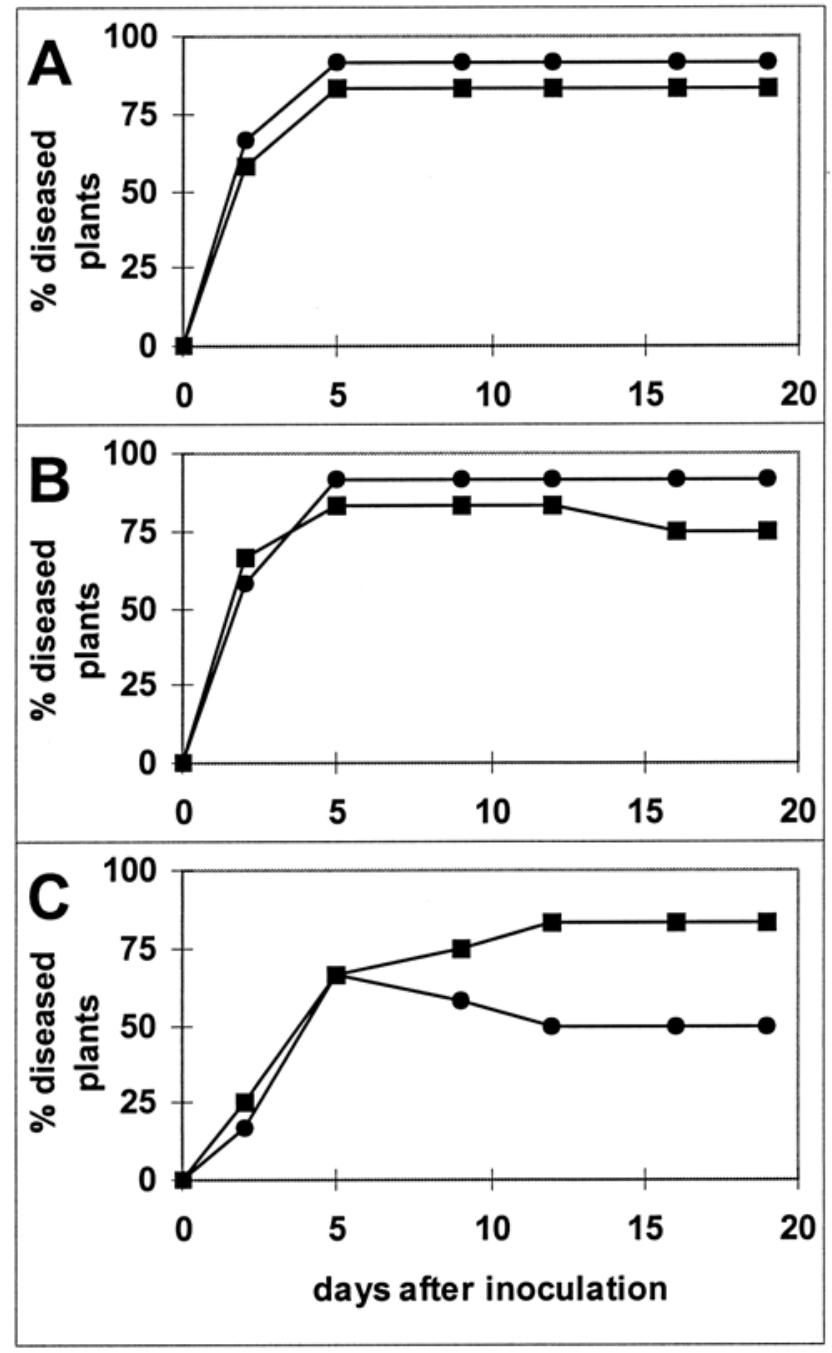

Fig. 3. Percentage of control $(\bullet)$ and transgenic ethylene-insensitive tobacco (Tetr18) (ם) plants showing disease symptoms after inoculation with a mycelial suspension of Pythium aphanidermatum of A, $12 \mathrm{~g} /$ liter, B, $1.2 \mathrm{~g} /$ liter, and $\mathbf{C}, 0.12 \mathrm{~g} /$ liter. 
Nt59d. When comparing shoot tissues of control and Tetr18 plants within the same disease class, Tetr18 contained substantially more pathogen than control plants. Possibly, the ethylene insensitivity leads to reduced symptom development, as described for other plant-pathogen interactions (Bent et al. 1992; Lund et al. 1998). However, the ethylene insensitivity of Tetr18 also results in enhanced susceptibility to Pythium spp. If reduced symptom development and increased disease susceptibility both are involved, the enhanced susceptibility of Tetr 18 plants is even more pronounced than can be concluded from disease symptoms alone.

An explanation for the increased shoot colonization of Tetr 18 plants would be an enhanced susceptibility of the shoot tissue to the pathogen. This possibility is supported by the observation that Tetr18 plants are susceptible to stem inoculation with $P$ thium spp., whereas control plants are not. Therefore, it can be hypothesized that roots of both control and Tetr18 tobacco plants are infected by Pythium spp., but subsequent colonization of the stem and leaf tissues occurs much more efficiently in Tetr18 than in control plants. As described by Martin (1995), Pythium spp. can differ in the extent to which root tissues are colonized. Such a difference in the extent of root colonization also may explain the observed (partial) recovery of control plants, but not Tetr18 plants, by 5 days after root inoculation. Control plants suffering from wilting symptoms due to colonization of root epidermal or cortical cells only might recover by producing new, uninfected roots that reestablish water transport. In contrast, when the pathogen colonizes and destroys the vascular stele and subsequently the stem tissues, as observed in Tetr18 plants, water transport cannot be restored. Additionally, ethylene-insensitive tomato and petunia plants were demonstrated to be impaired in their ability to make adventitious roots (Clark et al. 1999); therefore, it is conceivable that nontransformed tobacco plants also produce new roots more readily than Tetr18 plants after destruction of the root system.

Ethylene-insensitive Arabidopsis reacted similarly to infection by Pythium spp. This was clearly demonstrated by the ein21 mutants, which were enhanced susceptible compared with wild-type plants. Surprisingly, the etrl-1 mutant appeared to be as resistant as wild-type Arabidopsis. Triple-response assays revealed, however, that the etrl-1 mutant was less insensitive to ethylene than the ein2-1 mutant (Fig. 6). The remaining responsiveness to ethylene of the etr 1-1 mutant might be responsible for a similar resistance as in wild-type plants.

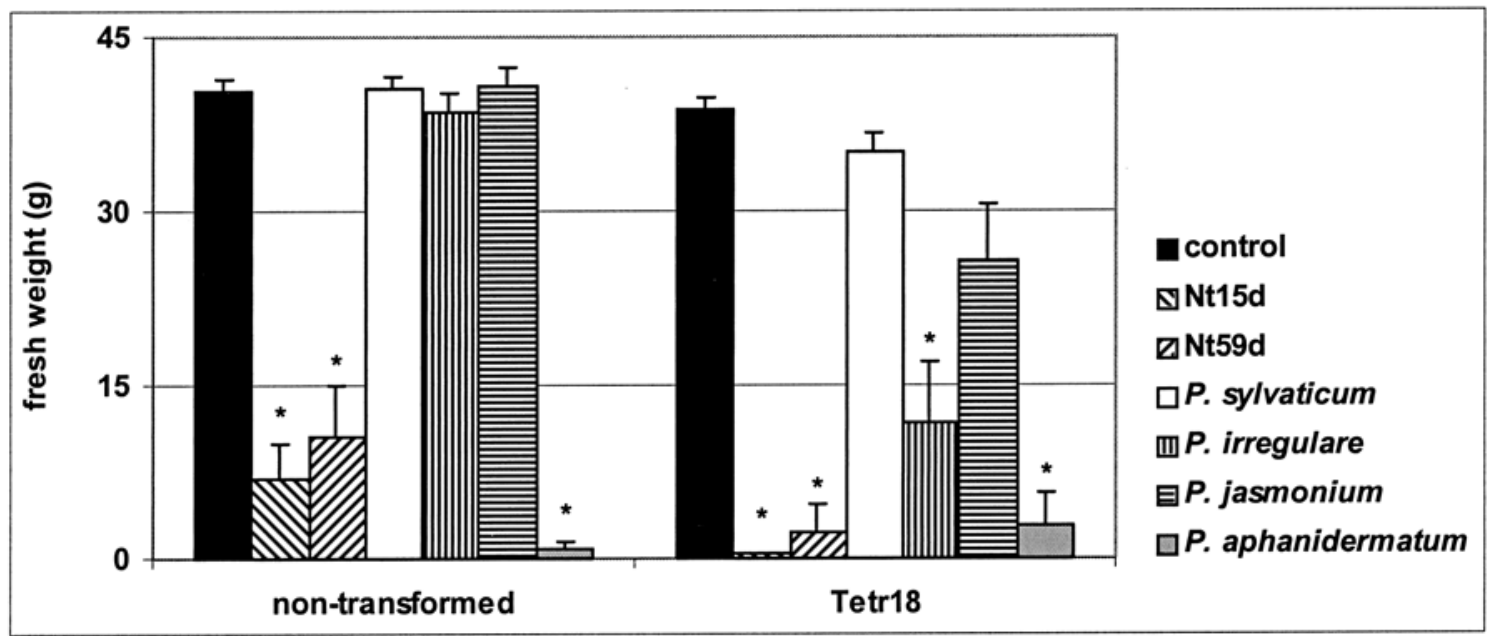

Fig. 4. Average shoot fresh weights of control and transgenic ethylene-insensitive tobacco (Tetr18) plants at 18 days after inoculation with different Pythium isolates. Error bars represent standard errors and an asterisk indicates a significant difference from mock-inoculated control plants.

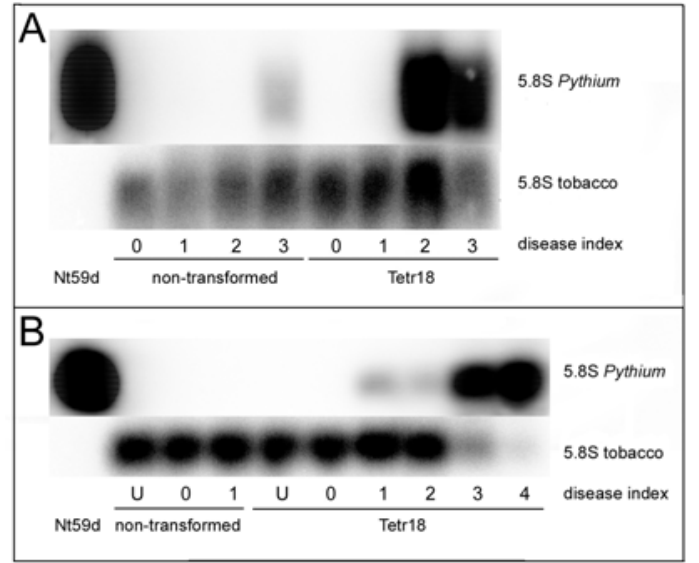

Fig. 5. Shoot colonization of control and transgenic ethylene-insensitive tobacco (Tetr18) plants by Pythium isolate Nt59d in two separate experiments. Five days after inoculation, shoots of A, 2-week-old seedlings or B, 4-week-old plants were pooled into groups according to their disease index and total RNA was extracted. The Northern blot was hybridized with probes that are specific for 5.8S ribosomal RNA of Pythium spp. or tobacco (loading reference). $\mathrm{U}=$ noninoculated plants.

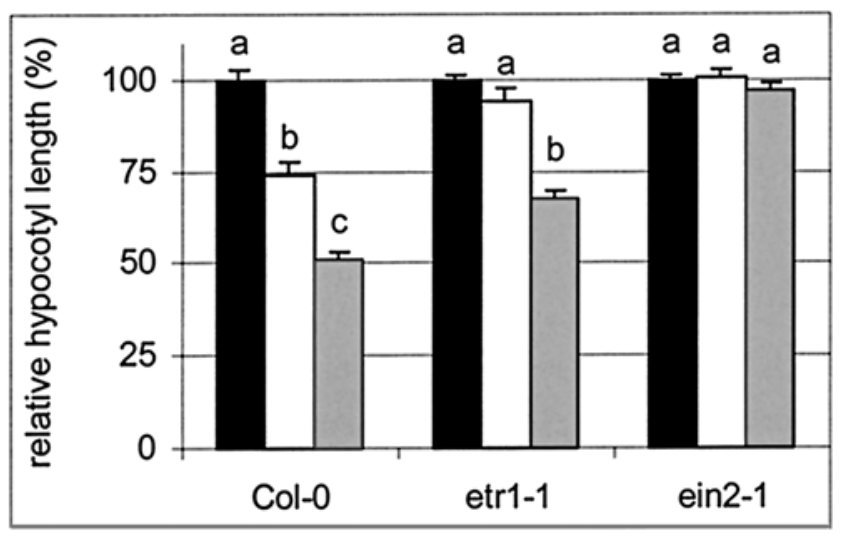

Fig. 6. 1-aminocyclopropane-1-carboxylic acid (ACC)-induced inhibition of hypocotyl growth. Seeds of wild-type and mutant etrl-1 and ein2-1 Arabidopsis were germinated on Murashige-Skoog agar medium containing 0 (black bars), 1 (white bars), or 5 (gray bars) $\mu \mathrm{M} \mathrm{ACC}$ at $4^{\circ} \mathrm{C}$ in the dark for 2 days. Hypocotyl lengths were measured after an additional growth period of 3 days at $20^{\circ} \mathrm{C}$ in the dark. Error bars represent standard errors and different letters within one genotype indicate significant differences. 
So far, enhanced susceptibility of Arabidopsis to P. irregulare (Staswick et al. 1998) and P. jasmonium (Vijayan et al. 1998) has only been demonstrated for JA-signaling mutants. We demonstrate here that, in Arabidopsis, resistance to five different $P y$ thium spp. also is dependent on ethylene signaling. Thomma et al. $(1998,1999)$ reported enhanced susceptibility of Arabidopsis to other necrotizing pathogens due to impaired ethylene or JA signaling, indicating that both ethylene and JA are important for resistance to necrotrophic pathogens in Arabidopsis (Thomma et al. 2001a, b). In tobacco, ethylene insensitivity also results in enhanced susceptibility to several necrotizing pathogens (i.e., Pythium spp., Fusarium spp., R. stolonifer, and T. basicola). This suggests that resistance to necrotrophic pathogens in tobacco and Arabidopsis depends on similar signal transduction pathways, and that both depend on ethylene.

Root invasion by Pythium spp. is characterized by a degradation of host cell walls. Plants may respond actively to $P y$ thium invasion by deposition of secondary wall thickenings and lignification (Martin 1995). Thus, cell wall structure appears to be a significant factor in Pythium resistance. Ethylene can alter lignification, cell wall synthesis, and cell wall composition (Abeles et al. 1992). Ethylene-insensitive tobacco and Arabidopsis plants show increased susceptibility to Pythium spp.; therefore, ethylene might play a crucial role in the reglation of cell wall formation before or after attack by Pythium spp. and other necrotizing pathogens. Further research on the role of ethylene in cell wall formation will be important to elucidate conserved mechanisms of resistance to a broad spectrum of pathogens.

\section{MATERIALS AND METHODS}

\section{Plant material.}

Tetr18 (Knoester et al. 1998) and corresponding nontransformed tobacco (Nicotiana tabacum cv. Samsun NN) plants were grown in a greenhouse with a cycle of $16 \mathrm{~h}$ of light at $24^{\circ} \mathrm{C}$ and $8 \mathrm{~h}$ of dark at $21^{\circ} \mathrm{C}$. Wild-type Arabidopsis thaliana ecotype Columbia (Col-0), its weakly ethylene-insensitive mutant etrl-1 (Bleecker et al. 1988), its strongly ethylene-insensitive mutant ein2-1 (Guzman and Ecker 1990), and its JA-insensitive mutant jarl-1 (Staswick et al. 1998) were grown in a growth chamber with a cycle of $8 \mathrm{~h}$ of light at $24^{\circ} \mathrm{C}$ and $16 \mathrm{~h}$ of dark at $20^{\circ} \mathrm{C}$. Seed were sown on river sand with halfstrength Hoagland nutrient solution $(300 \mathrm{ml} / \mathrm{kg})$ and grown for 2 weeks at relative humidity $(\mathrm{RH})=100 \%$. After 2 weeks, the seedlings were transplanted into 0.6 -liter pots ( $N$. tabacum) or 0.1-liter pots (A. thaliana) containing an autoclaved mixture of potting soil and river sand (12:5, vol/vol). RH was maintained at $70 \%$ and plants were watered two to four times a week. Once a week, the plants were supplied with half-strength Hoagland nutrient solution.

Triple-response assays with $A$. thaliana Col-0 and ethyleneinsensitive mutants etr $1-1$ and ein $2-1$ were performed as described previously (Ton et al. 2001).

Isolation and test for pathogenicity of fungi and oomycetes.

Stems of tobacco plants showing symptoms of wilt and stem necrosis were cut in pieces, which were rinsed with tap water and surface sterilized by incubation in $70 \%$ ethanol (60 s), $1 \%$
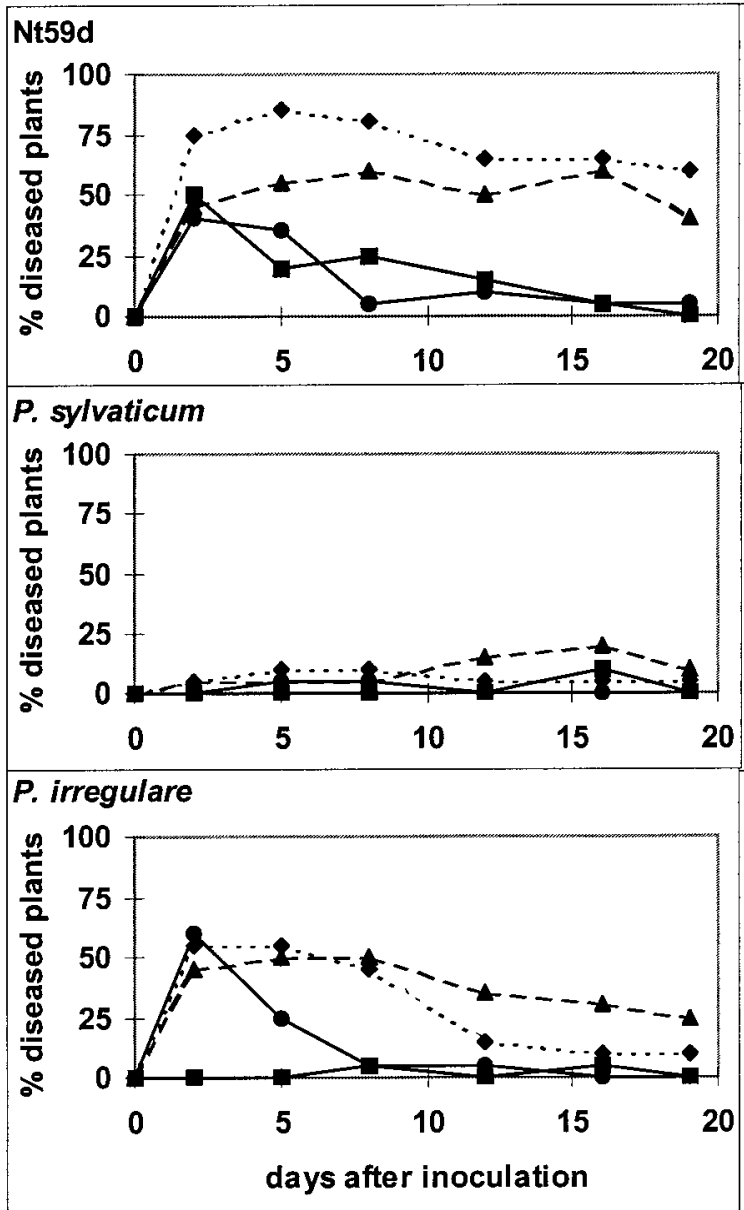

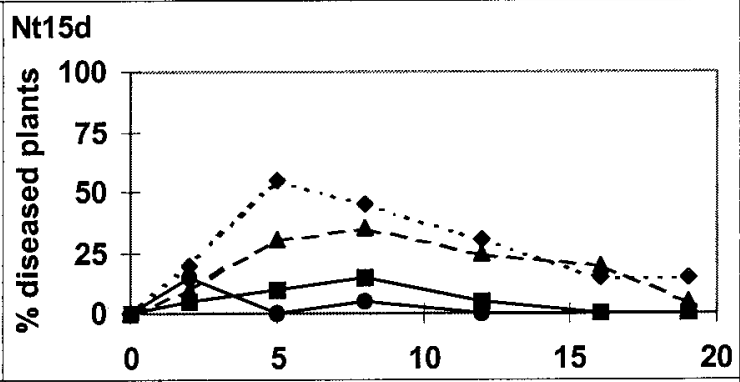

\section{P. jasmonium}

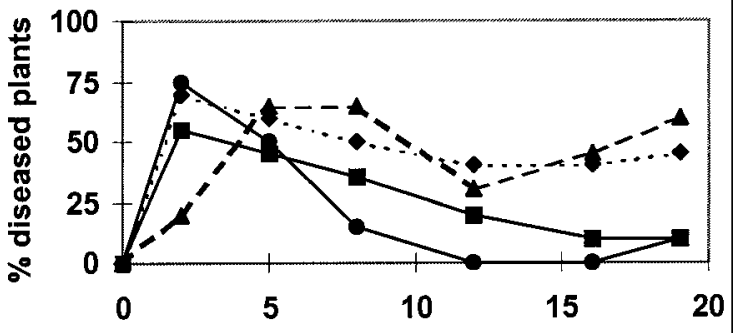

P. aphanidermatum

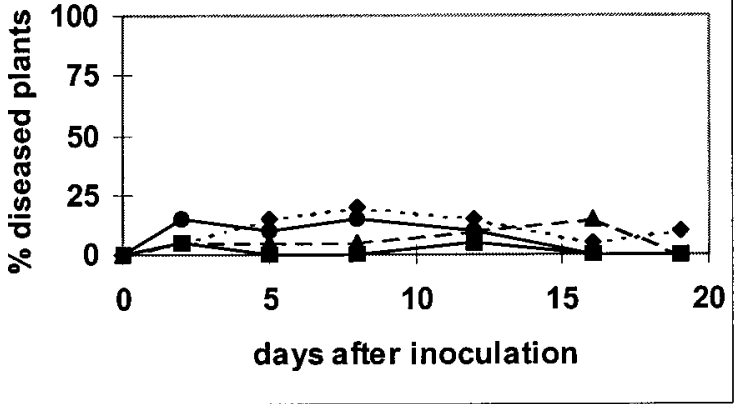

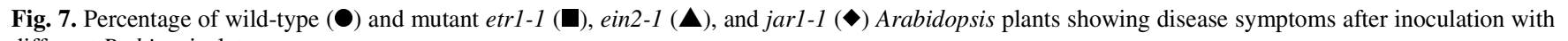
different Pythium isolates. 
$\mathrm{NaClO}_{3}$ (3 to $5 \mathrm{~min}$ ), and $70 \%$ ethanol (30 s), successively. The pieces were washed three times for 3 to $5 \mathrm{~min}$ in sterile water, cut into slices 2 to $4 \mathrm{~mm}$ thick, and patted dry on sterile filter paper. The slices were transferred to different agar media supporting growth of a wide variety of microorganisms (i.e., water agar, potato dextrose agar [Difco, Le Pont de Claix, France], or malt extract agar [2\% malt extract, Difco] medium with or without penicillin at $100 \mathrm{mg} / \mathrm{liter}$ and streptomycin at $200 \mathrm{mg} / \mathrm{liter}$ ). After 1 to 5 days of incubation at $23^{\circ} \mathrm{C}$, mycelium of developing fungal and oomycetous colonies was transferred to fresh agar medium. To test selected isolates for pathogenicity, five agar plugs $(8-$ by- $8 \mathrm{~mm}$ ) containing mycelium were placed against the stem base of 6-week-old control and Tetr tobacco plants growing in autoclaved soil.

\section{Pythium isolates and inoculation experiments.}

In addition to the isolates obtained from diseased Tetr18 plants in this study, four other Pythium isolates were used to inoculate tobacco and Arabidopsis plants: P. sylvaticum (Knoester et al. 1998), P. irregulare (Staswick et al. 1998), P. jasmonium (Vijayan et al. 1998; strain 101876, CBS, Baarn, The Netherlands), and $P$. aphanidermatum (Postma et al. 2000). Pythium isolates were grown on liquid V8 medium $(20 \%$ [vol/vol] V8 juice $+0.05 \mathrm{M} \mathrm{CaCO}_{3}, \mathrm{pH} 7.3$ ) at $25^{\circ} \mathrm{C}$ for 14 days. Mycelium was washed three times in distilled water, patted dry, weighed, and homogenized in distilled water with a blender for $30 \mathrm{~s}$. Some isolates did not produce oospores in vitro; therefore, suspensions were adjusted to a mycelial mass of $15 \mathrm{~g} / \mathrm{liter}$.

For root inoculation of tobacco and Arabidopsis, roots of 2week-old seedlings were dipped for 1 to $2 \mathrm{~s}$ in distilled water (mock inoculation) or a mycelial suspension prior to transplanting in the soil-sand mixture. For each treatment, 12 tobacco or 20 Arabidopsis plants were used. For stem inoculation of tobacco, 5- to 6-week-old plants were placed horizontally and a $20-\mu \mathrm{l}$ droplet of distilled water (mock inoculation) or mycelial suspension was applied onto the stem. Three needle pricks were applied through the droplet. One day later, the plants were placed in their vertical position again.

All inoculation experiments were repeated at least once with similar results.

\section{Quantification of disease symptoms.}

Disease severity was assessed using a d.i. score where $0=$ no disease symptoms; $1=$ less than $30 \%$ of leaves wilting; $2=$ more than $30 \%$ of leaves wilting, sometimes first symptoms of stem (base) necrosis; 3 = all leaves wilting, necrosis of stem (and leaf) tissue; and $4=$ plant completely necrotic. By the end of each experiment, fresh weights of the shoots were determined. Differences in the percentages of plants showing disease symptoms (d.i. $=1$ and higher) were statistically analyzed using the repeated measures option of the statistical program SPSS 8.0 for Windows. Statistical analysis of the shoot weight data was performed using independent samples $t$ tests and Bonferroni correction. Triple-response assays were statistically analyzed by one-way analysis of variance.

\section{Colonization of tobacco by Pythium sp.: RNA isolation and Northern blotting.}

Up to 200 plants of young control and Tetr18 tobacco were inoculated with Pythium isolate Nt59d by root dip as described above. After 5 days, plants were divided into groups on the basis of their d.i. and total RNA from shoot tissue was extracted. Stem and leaf tissue was ground in liquid nitrogen, suspended in an equal volume of extraction buffer $(0.35 \mathrm{M}$ glycine, $0.048 \mathrm{M}$ $\mathrm{NaOH}, 0.34 \mathrm{M} \mathrm{NaCl}, 0.04 \mathrm{M}$ EDTA, $4 \%$ [wt/vol] sodium dodecyl sulfate [SDS]), and incubated on ice for $5 \mathrm{~min}$. RNA was extracted with phenol/chloroform/isoamylalcohol (25:24:1 [vol/vol] ) and precipitated with one-third volume of $8 \mathrm{M} \mathrm{LiCl}$ at $4^{\circ} \mathrm{C}$, as described by Sambrook and associates (1989).

One microgram of RNA was denatured using glyoxal and dimethyl sulfoxide as described by Sambrook and associates (1989) and separated by gel electrophoresis on 1.5\% agarose gels in $10 \mathrm{mM}$ sodium phosphate buffer ( $\mathrm{pH}$ 7.0). The RNA was blotted onto Hybond- $\mathrm{N}^{+}$membrane (Amersham Pharmacia Biotech, Roosendaal, The Netherlands) by capillary transfer, using a 25-mM sodium phosphate solution ( $\mathrm{pH} 7.0)$ as blotting buffer. The membrane was washed in $20 \mathrm{mM}$ Tris-Tris- $\mathrm{HCl}(\mathrm{pH} \mathrm{8.0)}$ and prehybridized in 7\% SDS, $1 \mathrm{mM}$ EDTA, and $0.5 \mathrm{M}$ sodium phosphate ( $\mathrm{pH} 7.2$ ). Hybridization was performed at $65^{\circ} \mathrm{C}$ with a random-prime- $\alpha-{ }^{32} \mathrm{P}-$ labeled (Ready-To-Go labeling kit; Amersham Pharmacia Biotech) probe that was specific for 5.8S ribosomal RNA of Pythium isolate Nt59d (see below). The membrane was rinsed once in $0.3 \mathrm{M} \mathrm{NaCl}, 0.037 \mathrm{M}$ Na-citrate, and $0.5 \%$ SDS, washed three times in the same solution at hybridization temperature for $15 \mathrm{~min}$, and exposed to a Molecular Imager FX screen (Bio Rad, Veenendaal, The Netherlands).

\section{Development of the 5.8S RNA specific probes.}

In order to obtain a probe that is specific for the ribosomal RNA of Pythium spp., polymerase chain reaction (PCR) primers

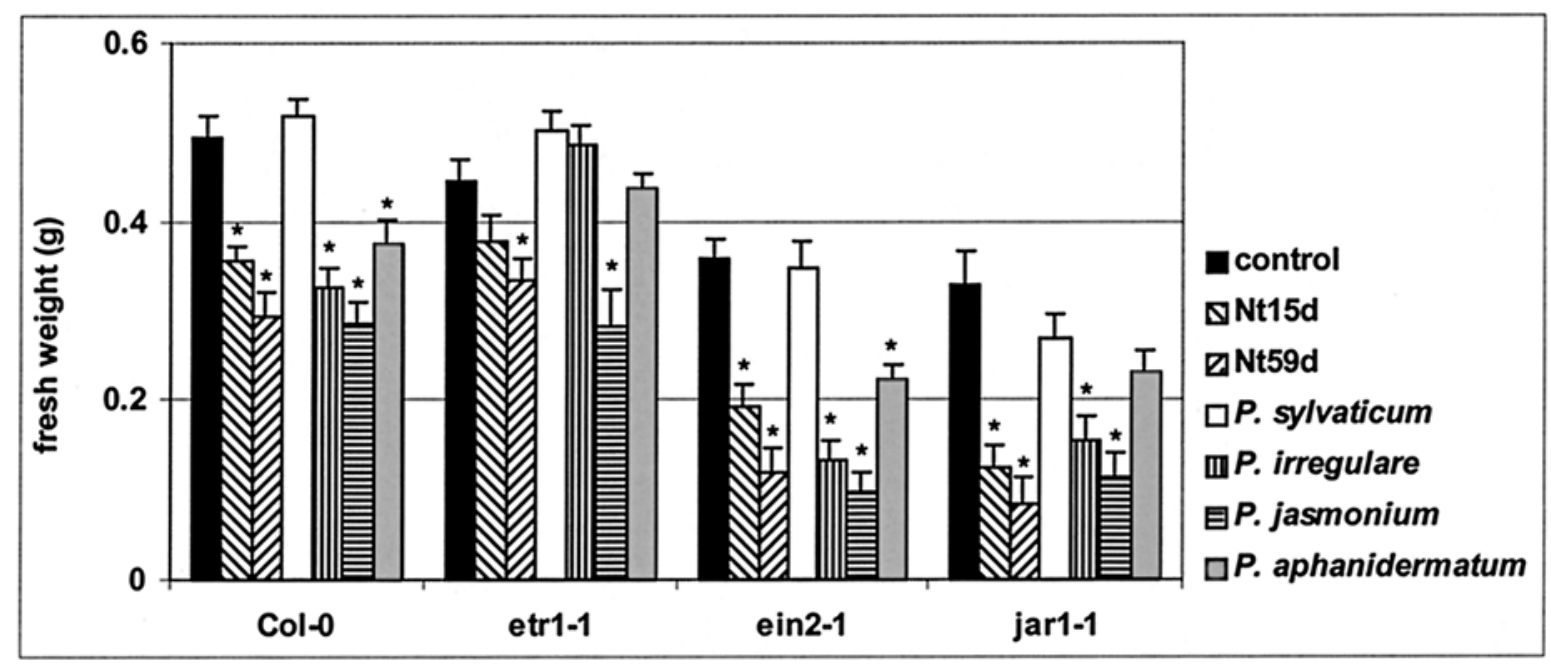

Fig. 8. Average shoot fresh weights of wild-type, etr1-1, ein2-1, and jar1-1 Arabidopsis plants at 19 days after inoculation with different Pythium spp. Error bars represent standard errors and an asterisk indicates a significant difference from mock-inoculated control plants. 
were developed based on ribosomal DNA sequences that are conserved among Pythium spp. Sequences of P. ultimum (accession number D86515) and closely related oomycetes (Peronospora manshurica [AB021711], P. destructor (AB021712), Phytophthora sojae [L41385], and P. nicotianae [L41383]) were aligned by computer (MegAlign, DNASTAR, Madison, WI, U.S.A.). From two conserved sequences, a forward ( $5^{\prime}-$ GAAGGATCATTACCACAC-3') and reverse (5'-TACGGACACTGATACAG-3') primer were selected (PrimerSelect, DNASTAR) that amplified a 390-bp fragment of the $P$. ultimum rDNA containing internal transcribed spacer 1 and the complete $5.8 \mathrm{~S}$ subunit. A PCR was performed using genomic DNA of Pythium isolate Nt59d as a template. The amplicon was labeled and used as a probe as described above.

A probe that is specific for ribosomal RNA of tobacco was developed in a similar way. Ribosomal sequences of tobacco cvs. Bright Virginia, Burley, Havana, Kentucky, and Xanti Yaka (accession numbers AJ012358, AJ012359, AJ012362, AJ012364, and AJ012367)were aligned. The selected forward (5'-GCGGGGGACTTGTGCTTCTTTTGA-3') and reverse (5'-TCGCCGTGGACTCGCATTTAGG-3') primers amplified a 310-bp fragment of the rDNA containing the complete $5.8 \mathrm{~S}$ subunit. Genomic DNA of tobacco cv. Samsun NN was used as template in the PCR.

\section{ACKNOWLEDGMENTS}

This research was financially supported by the Earth and Life Sciences Foundation (ALW), which is subsidized by the Netherlands Organisation for Scientific Research (NWO). We thank J. Postma and P. Staswick for kindly providing isolates of $P$. aphanidermatum and $P$. irregulare, respectively; A. de Cock and R. A. Samson of the Fungal Biodiversity Center (Utrecht, The Netherlands) for identification of fungal isolates, and J. Ton for providing the data on the triple-response assays.

\section{LITERATURE CITED}

Abeles, F. B., Morgan, P. W., and Saltveit, M. E., Jr. 1992. Ethylene in plant biology. Academic Press Inc., San Diego, CA, U.S.A.

Bent, A. F., Innes, R. W., Ecker, J. R., and Staskawicz, B. J. 1992. Disease development in ethylene-insensitive Arabidopsis thaliana-infected with virulent and avirulent Pseudomonas and Xanthomonas pathogens. Mol. Plant-Microbe Interact. 5:372-378.

Bleecker, A. B., Estelle, M. A., Somerville, C., and Kende, H. 1988. Insensitivity to ethylene conferred by a dominant mutation in Arabidopsis thaliana. Science 241:1086-1089.

Boller, T. 1991. Ethylene in pathogenesis and disease resistance. Pages 293-314 in: The Plant Hormone Ethylene. K. Mattoo and J. C. Suttle, eds. CRC Press, Inc., Boca Raton, FL, U.S.A.

Chen, J., Jacobson, L. M., Handelsman, J., and Goodman, R. M. 1996. Compatibility of systemic acquired resistance and microbial biocontrol for suppression of plant disease in a laboratory assay. Mol. Ecol. 5:73-80.

Clark, D. G., Gubrium, E. K., Barrett, J. E., Nell, T. A., and Klee, H. J. 1999. Root formation in ethylene-insensitive plants. Plant Physiol. 121:53-59.

Guzman, P., and Ecker, J. R. 1990. Exploiting the triple response of Arabidopsis to identify ethylene-related mutants. Plant Cell 2:513-523.

Hoffman, T., Schmidt, J. S., Zheng, X., and Bent, A. F. 1999. Isolation of ethylene-insensitive soybean mutants that are altered in pathogen susceptibility and gene-for-gene disease resistance. Plant Physiol. 119:935949.

Knoester, M., Linthorst, H. J. M., Bol, J. F., and Van Loon, L. C. 2001. Involvement of ethylene in lesion development and systemic acquired resistance in tobacco during hypersensitive reaction to tobacco mosaic virus. Physiol. Mol. Plant Pathol. 59:45-57.

Knoester, M., Van Loon, L. C., Van den Heuvel, J., Hennig, J., Bol, J. F., and Linthorst, H. J. M. 1998. Ethylene-insensitive tobacco lacks nonhost resistance against soil-borne fungi. Proc. Natl. Acad. Sci. U.S.A. 95:1933-1937.

Lund, S. T., Stall, R. E., and Klee, H. J. 1998. Ethylene regulates the susceptible response to pathogen infection in tomato. Plant Cell 10:371382.

Martin, F. N. 1995. Pythium. Pages 17-36 in: Pathogenesis and Host Specificity in Plant Diseases. K. Kohmoto, U. S. Singh, and R. P. Singh, eds. Pergamon Press Inc., New York.

Martin, F. N., and Loper, J. E. 1999. Soilborne plant diseases caused by Pythium spp.: ecology, epidemiology, and prospects for biological control. Crit. Rev. Plant. Sci. 18:111-181.

Norman-Setterblad, C., Vidal, S., and Palva, E. T. 2000. Interacting signal pathways control defense gene expression in Arabidopsis in response to cell wall-degrading enzymes from Erwinia carotovora. Mol. PlantMicrobe Interact. 13:430-438.

Penninckx I. A. M. A., Eggermont, K., Terras, F. R. G., Thomma, B. P. H J., De Samblanx, G. W., Buchala, A., Métraux, J., Manners, J. M., and Broekaert, W. F. 1996. Pathogen-induced systemic activation of a plant defensin gene in Arabidopsis follows a salicylic acid-independent pathway. Plant Cell 8:2309-2323.

Penninckx, I. A. M. A., Thomma, B. P. H. J., Buchala, A., Métraux, J., and Broekaert, W. F. 1998 Concomitant activation of jasmonate and ethylene response pathways is required for induction of a plant defensin gene in Arabidopsis. Plant Cell 10:2103-2113.

Pieterse, C. M. J., Van Wees, S. C. M., Van Pelt, J. A., Knoester, M., Laan, R., Gerrits, H., Weisbeek, P. J., and Van Loon, L. C. 1998. A novel signaling pathway controlling induced systemic resistance in Arabidopsis. Plant Cell 10:1571-1580.

Postma, J., Willemsen-de Klein, M. J. E. I. M., and Van Elsas, J. D. 2000. Biological control-Effect of the indigenous microflora on the development of root and crown rot caused by Pythium aphanidermatum in cucumber grown on rockwool. Phytopathology 90:125-133.

Sambrook, J., Fritsch, E. F., and Maniatis, T. 1989. Molecular Cloning: A Laboratory Manual, 2nd ed. Cold Spring Harbor Laboratory Press, Cold Spring Harbor, NY, U.S.A.

Staswick, P. E., Yuen, G. Y., and Lehman, C. C. 1998. Jasmonate signaling mutants of Arabidopsis are susceptible to the soil fungus Pythium irregulare. Plant J. 15:747-754.

Thomma, B. P. H. J., Eggermont, K., Penninckx, I. A. M. A., Mauch-Mani, B., Vogelsang, R., Cammue, B. P. A., and Broekaert, W. F. 1998. Separate jasmonate-dependent and salicylate-dependent defense-response pathways in Arabidopsis are essential for resistance to distinct microbial pathogens. Proc. Natl. Acad. Sci. U.S.A. 95:15107-15111.

Thomma, B. P. H. J., Eggermont, K., Tierens, K. F. M.-J., and Broekaert W. F. 1999. Requirement of functional ethylene-insensitive 2 gene for efficient resistance of Arabidopsis to infection by Botrytis cinerea. Plant Physiol. 121:1093-1101.

Thomma, B. P. H. J., Penninckx, I. A. M. A., Broekaert, W. F., and Cammue, B. P. A. 2001a. The complexity of disease signaling in Arabidopsis. Curr. Opin. Immunol. 13:63-68.

Thomma, B. P. H. J., Tierens, K. F. M., Penninckx, I. A. M. A., MauchMani, B., Broekaert, W. F., and Cammue, B. P. A. 2001b. Different micro-organisms differentially induce Arabidopsis disease response pathways. Plant Physiol. Biochem. 39:673-680.

Ton, J., Davison, S., Van Wees, S. C. M., Van Loon, L.C., and Pieterse, C. M. J. 2001. The Arabidopsis ISRI locus controlling rhizobacteria-mediated induced systemic resistance is involved in ethylene signaling. Plant Physiol. 125:652-661.

Ton, J., Van Pelt, J. A., Van Loon, L.C. and Pieterse, C. M. J. 2002. Differential effectiveness of salicylate-dependent and jasmonate/ethylene-dependent induced resistance in Arabidopsis. Mol. Plant-Microbe Interact. 15:27-34.

Vijayan, P., Shockey, J., Lévesque, C. A., Cook, R. J., and Browse, J. 1998. A role for jasmonate in pathogen defense of Arabidopsis. Proc. Natl. Acad. Sci. U.S.A. 95:7209-7214. 